\title{
Organizational dynamics of technology-based innovation: diversifying the research agenda
}

\author{
David G Wastell ${ }^{1}$, Tom McMaster ${ }^{2}$ \\ ${ }^{1}$ Nottingham University Business School, Jubilee Campus, Nottingham, UK \\ ${ }^{2}$ Salford Business School, University of Salford, Greater Manchester, UK \\ Correspondence: \\ DG Wastell \\ Nottingham University Business School, Jubilee Campus, Wollaton Road, Nottingham NG8 1BB, UK. \\ Tel: +440115 $846 \mathbf{7 7 8 3}$; \\ Fax: + 4401158466667 ; \\ E-mail: david.wastell@nottingham.ac.uk
}

Journal of Information Technology (2008) 23, 63-70. doi:10.1057/palgrave.jit.2000133

\section{Introduction}

Ordnung ist heutzutage meistens dort, wo nichts ist.

Es ist eine Mangelerscheinung-BRECHT

S ince its formal inception in 1994, Working Group 8.6 of the International Federation for Information Processing (IFIP) has held 10 working conferences. The remit of the Group is to act as a dedicated forum within the information systems (IS) community for research on the 'Adoption, Diffusion and Implementation of Information Technologies'. The first four conferences were held in Oslo (October 1995); Ambleside, UK (June 1997); Helsinki (December 1998); and Banff, Canada (April 2001). More recently a pattern of annual gatherings has stabilized, with meetings in Sydney (2002); Copenhagen (2003); Leixlip, Ireland (2004); Atlanta (2005) and Galway (2006). The 10th Conference of WG8.6 was held in Manchester (UK) in June 2007, under the general theme given by the title of this Editorial. We were deeply honoured when Gordon Davis accepted our invitation to be the General Chair, given his long-standing involvement with the Group. The overall aim was to take stock of progress and to revivify the Group's research agenda (if such tonic were needed) through expanding the range of theories and methods deployed in our endeavours, and treading into empirical terrains that we may have neglected heretofore. The full proceedings are reported in McMaster et al. (2007) and a selection of five papers is published in this issue of JIT. The purpose of this essay is to provide an overview of the Conference as a whole, reviewing the various contributions and teasing out some general themes.

In our Editorial for the Proceedings (Wastell and McMaster, 2007) we began, as here, with the epigraph ${ }^{1}$ used by Paul Feyerabend to open his seminal monograph Against Method (Feyerabend, 1993). It seemed apt to invoke Feyerabend in the context of a Conference devoted to diversification. The gist of Feyerabend's thesis is captured in the following extracts:

Science is an essentially anarchistic enterprise: theoretical anarchism is more humanitarian and more likely to encourage progress than its law-and-order alternative (ibid.: 9). This is shown both by an examination of historical episodes and by an abstract analysis of the relation between idea and action. There is only one principle that can be defended under all circumstances and in all stages of human development. It is the principle: anything goes (ibid.: 18-19). The attempt to increase liberty, to lead a full and rewarding life, and the corresponding attempt to discover the secrets of nature and of man, entails therefore the rejection of all universal standards and rigid traditions [imposed] upon research and upon any kind of knowledge-creating and knowledgechanging activity (ibid.: p. 12).

Two points stand out here. First, that the argument for methodological anarchy is empirical, as well as theoretical and ethical: it is carefully grounded on an extensive historical analysis of how science actually develops. ${ }^{2}$ Second, Feyerabend indivisibly links the causes of liberty and science, connecting dogma of method and theory not only with epistemological stasis but with human oppression; hence, our Brechtian grace note. Such eclecticism and unorthodoxy finds strong resonance in the general traditions of WG8.6, as was noted by Davis in his thoughtful, personal foreword to the Proceedings (McMaster et al. 2007: xii-xiii):

I started my academic career as a traditional positivist. It was in Manchester in 1984 at a conference on information systems research sponsored by WG 8.2 that I had an epiphany. My eye-opening experience did not convert 
me to a complete post-positivist ... rather, it expanded my thinking to encompass a much broader range of research paradigms... WG 8.2 might have been organized with tight boundaries that excluded different research paradigms; it didn't happen that way. WG 8.6 was organized as a home for a diverse research agenda with openness for different research paradigms. This working conference continues the tradition.

Our Editorial went on to aver that if anarchy is such 'excellent medicine for epistemology' (Feyerabend, p. 9), then it was surely apt to check out the intellectual health of our community. We borrowed from Stoler (2002) the intriguing idea of archives as 'epistemological experiments'. Although she was specifically concerned with colonial archives, the argument readily extends to other institutions and technologies of knowledge creation. This naturally embraces conferences which, by design, leave an archival trace, in the durable form of books as well as more ephemeral documents (reviews, decision letters, minutes, e-mails, etc.). Stoler contends that scholars should view archives not as repositories to be passively mined for 'facts' but as situated loci of knowledge production, 'of taxonomies in the making'. Interest shifts to what constitutes the archive, what form it takes, the systems of classification it embodies, and so on. In other words, what does the archive as a cultural artefact reveal about the nature of the world that produced it, and of the ambient politics of knowledge.

Given its stated theme, it seemed particularly apposite to use the Manchester conference as an object of reflexive, epistemological study! In the following sections, we provide an overview of the methodology used in selecting papers and constructing the programme, before proceeding to a conspectus of the meeting's content. We will then stand back and make a critical appraisal of the results of our epistemological experiment. To assess theoretical progress, we shall draw on Flynn and Gregory's (2004) survey of the prevalence of theory in IS research (based on conferences of IFIP WG8.2, a larger community subsuming many habitués of WG8.6) supplemented by our own retrospections as WG8.6 veterans. We were involved in developing the programme for the 1997 Conference, which provides a handy 10-year reference point (McMaster et al., 1997a).

\section{Purity, plurality and the politics of knowledge}

Let us preface our discussion of the conference methodology with another brief anthropological detour, again tracing the steps of our original Editorial. Through the concept of 'dirt', understood generically as 'matter out place', Mary Douglas (2002) established a bridge between the sophisticated contemporary world and other cultures that we conventionally dub as primitive. What they taboo, we denounce as dirty! In both cases, a threat or danger to the existing social order is controlled, either through avoidance (e.g. taboo foods) or via the enactment of purification rituals (e.g. ritual bathing). The association of danger with dirt is the key to this defensive structure. But what is classified as dirt or pollution is a matter of perspective and vested interest: 'there is no such thing as absolute dirt: it exists in the eye of the beholder' (Douglas, 2002). Turning to the world of orthodox science, our
Editorial teasingly enquired (but with serious intent too) whether the much-cherished peer-review process, for instance, constituted a modern hygiene ritual. Certainly, in following a formulaic pattern, it has all the appearance of ritual. And does not the fervour to quarantine defective (infective?) papers also draw on the same exaggerated conflation of dirt and danger that is characteristic of primitive 'pollution beliefs'?

Although rigorous selection policies are ubiquitous for learned journals, they are untypical in many disciplines when it comes to the selection of conference contributions. An inclusion agenda would seem to guide the selection of papers in other fields, with decisions based on abstracts and minimum entry criteria. Our field is different; the standard mechanism for the soi-disant 'top conferences' involves the submission of full papers and the application of a journallike peer-review process. Often this results in very low acceptance rates. This is taken as a proxy of quality, but taking a more critical stance, such exclusive sorting would seem inimical to scholarly debate and community development. Why do we set such stall by rejecting papers; why is this good? To an outsider, it would seem perverse to mark prestige in this way. Surely a high rejection rate implies a collective failure of scholarship not the intellectual prosperity of a field. And how, we may cogently ask, is the advancement of knowledge to be promoted by excluding the majority of candidate scholars? Rejected papers may fail to meet our epistemological standards, but they may yet contain ideas of value and interest, stimulating debate or otherwise destabilizing the status quo. As Feyerabend quips:

There is no idea, however ancient and absurd, that is not capable of improving our knowledge (ibid.: 33)

Guided by these precepts, an inclusion policy underpinned our selection procedures. But the politics of knowledge is no different from politics in general; it is the art of the possible. We therefore chose to innovate around the edges, adapting established editorial practices rather than attempting revolutionary change.

Three forms of contribution were sought: full research papers, short position papers of a polemical nature and panel proposals. All papers were blind-reviewed by two independent referees, and we as programme co-chairs also read every item. Overall, we received a total of 40 submissions. Twentynine of these were full research papers, 21 of which survived the review process. We saw much merit in many of the papers that failed to come through and the majority of authors were invited to revise and resubmit their submissions as position papers. We were delighted that almost all agreed. Together with the papers originally in this category, there were 14 position papers in all. Through this work-around, we had achieved our editorial goal, of maximizing attendance at the conference in the interests of intellectual diversity and building the research community. Almost all who had wanted to come and have their say were provided with an opportunity to be heard. Davis speaks approvingly of this device in his foreword: 'An interesting innovation is the publication of 14 position papers that present interesting ideas but don't fit the traditional model of conference papers'. 
Invited papers were also solicited from several leading academics and from two practitioners, representing the public and the commercial sectors locally. Given the Group's commitment to relevant research, we were delighted that both David Carter (Manchester City Council) and Gerry Pennell (CIO, Cooperative Financial Services) accepted these invitations, with a paper from Carter being published in the book. Gallier's key-note address and two panel summaries complete the published collection.

Acknowledging the arbitrariness of any taxonomy, especially where there are multiple criteria, we nonetheless attempted to allocate the papers to a set of appropriate categories, and the Proceedings were organized in corresponding sections (see the Appendix). The first three were as follows: Novel Perspectives in Innovation Research, Software Process Improvement and Actor Network Theory. Following a 'Technological Interlude' (focusing on Radio Frequency Identification) the final subset of papers provided examples of factor-style research examining IT adoption at the firm level. The final two sections in the book included the position papers and the panels. The former covered an eclectic range of topics, and were typically polemical and provocative in their core arguments. Regarding the panels, one addressed complexity theory, arguing for and against its contribution to innovation research; the second provided an international perspective on the diffusion of broadband technology. Full details of the contents of the Proceedings are given in the Appendix. Subsequently, we selected a number of papers for publication in this issue of JIT; these papers are previewed in the following section.

\section{Commentary on selected papers}

Five papers were selected for publication here. The criteria that guided our selection were as follows. We were looking for a set of papers that represented the range of topics covered in the Conference, and which had both significant empirical content and some theoretical novelty. The results of the peer-review process also influenced our decisions. Our recommendations were then discussed and agreed with one of the chief editors of the journal. Feedback outlining suggestions for improving the papers was given to the authors, and the revised versions were approved in the normal way. Some brief comments on the selected papers now follow, in the chapter order in which they appear in the Proceedings.

Reflecting the conference theme, the first two of our selections were drawn from the group of papers (Part 2) that we felt best-exemplified significant innovation in theory and method. The first by Bunker, Kautz and Anhtuan (Chapter 7 in the Proceedings) opens up an anthropological perspective on issues of adoption and rejection of IS artefacts, representing a new approach to these enduring problems. Bunker et al. focus on potential differences in organizational culture between the contexts of IS development and IS use, arguing that the vicissitudes of implementation could often reflect incompatible assumptions, values and skills. The paper reports a naturally occurring experiment, with the same artefact (a timesheet application) being implemented in two culturally distinct contexts in the same user organization. Differences in attitudes to managerial control were found to influence the contrasting fortunes of the artefact in these neighbouring settings. The paper provides a succinct but comprehensive overview of relevant anthropological theory in which the treatment of skill as a dimension of culture is a distinctive feature.

Igíra's paper (Chapter 9) is noteworthy for its use of Activity Theory, which has attracted steady though desultory interest over the years within the IS discipline (Flynn and Gregory, 2004). The paper begins with a very thorough and readable account of CHAT (Cultural Historical Activity Theory) emphasizing its ability to address 'the mutual shaping of context and work practice'. There follows a fascinating description of the health-care setting in Tanzania, which is used to illustrate the way that contextual influences from the management domain (e.g. the need to generate statistical information) create tensions at the operational level and how these have prompted the development of new local tools. There are some intriguing ethnographic insights, for example, the vulnerability of paper-based IS to the ravages of the local fauna (ants and rats), and the massaging of data in order to optimize financial revenues in the private health care sector.

Two of the selected papers adopted Actor Network Theory (Latour, 1987; McMaster et al., 1997b) as their primary theoretical lens. In Flynn and Gregory's (2004) league table, actor network theory (ANT) comes out as the most commonly deployed framework within the deliberations of IFIP WG8.2. Elbanna (Chapter 17) takes the idea of 'modalities' from Latour (1987). She is concerned with shifting trajectories, or 'drift', over the course of project life cycles. Whereas positive modalities strengthen the formation of 'black boxes', negative ones question the emergent status quo, and potentially move the project in different directions. This novel conceptualization is well illustrated in a detailed account of an ERP implementation. The paper gives very useful insights into the dynamics of drift and the range of contingencies that influence the vector of innovation in large technology projects, perhaps taking it far from its original track. These ideas could readily be extended to other domains, and their practical relevance to implementers is also pointed out.

Rodon, Pastor and Sesé (Chapter 20) provide an excellent exposition of the main tenets of ANT, of problematization, interressement, enrollment, inscription, mobilization, black boxing and so forth. Most impressive of all are the empirics of this paper. The authors use their ANT-based framework to track the evolution of a complex inter-organizational IS in the Port of Barcelona. The purpose of the system is to coordinate logistical activity and integrate all the information exchanged among port agents and public bodies. The account covers an 11-year period, tracing out five 'translation cycles' between 1994 and 2005 as the actor-network changes its configuration over time. The focus on the 'obligatory point of passage' as the contested centre of key power struggles forms an important part of the unfolding drama. The paper makes a very useful contribution in showing how the deployment of a structured analytical schema based on ANT can be used to capture the long-term dialectics of technological change.

Finally, the paper by Vega, Chiasson and Brown (Chapter 25 ) is of particular interest in two areas. Theoretically, it 
extends the core DOI (Diffusion of Innovation) model to address broader 'network-based' influences, specifically those emanating from the macro economic development policies of central governments. Addressing the role of government support is timely given the hubristic enthusiasm of the State (in the UK certainly) for intervening in all public spheres. The all-too-common failure of such 'public programme' interventions to deliver hoped-for benefits often reflects the unintended consequences arising from the perverse incentives that they inadvertently set up. The authors present a detailed case study illustrating the daunting range of structural factors that inhibit the effectiveness of such initiatives and the moral hazards that they inevitably pose. The paper elegantly illustrates a common dysfunction, namely the tendency for programmecentric goals (e.g. hitting targets for take-up) to displace the real aim of providing useful help for business clients.

\section{Overview of the remaining full papers}

In this section, we provide brief comments on the remaining material, in chapter-by-chapter order, restricting our synopsis to full papers only, given space limitations.

\section{Keynotes and invited papers}

In his extended abstract, Galliers passionately took up the conference theme, arguing for greater diversity and innovation in method as well as topic in IS research. Challenging recent calls to narrow our research focus, he highlighted the expanding boundary of the field and what this means for the IS academy. He argued that it is only through an exploratory, trans-disciplinary approach to our research (encompassing societal, ethical and global issues) that innovation and diversity are to be fostered.

Carter's paper provided an intriguing account of how the City of Manchester has addressed the 'digital divide' and urban regeneration through the Manchester Digital Development Agency (MDDA). This draws together a number of interconnected 'e-based' initiatives at local, regional, national and European-wide levels. He describes in detail the 'Eastserve Project' and how it addressed deprivation and social exclusion. The work of ONE-Manchester (Open Network E-Manchester) is also outlined, which embraces various local government neighbours as well as some private industry partners.

Truex and Holmström's stimulating essay was also right on the conference theme. Like Galliers, they also see the dangers of a totalizing tendency in the IS field, which they dub the 'supremacist strategy - a strategy aiming at establishing one theoretical approach as universally applicable'. They call on IS scholars to 'drop your tools - to hold your concepts lightly and update them frequently' (the original exhortation comes from Karl Weick).

León's paper discussed the merits of 'open innovation' partnerships, with an emphasis on technology transfer. $\mathrm{He}$ describes three similar, but crucially different innovation models: the subcontracted model, the cooperative model, and the open community model. These are set in the context of European policy instruments for technology transfer. León advocates greater cooperation between governments, universities and private sector organizations to exploit and benefit from such partnerships.
The distinction between factor and process perspectives is often made in delineating genres of IS research. Newman and Zhu's paper hailed the richer causal narratives yielded by longitudinal research, which is able to map the shifts in project trajectories triggered by supervening events (critical incidents). The paper describes the application of their punctuated equilibrium model to the development of an IS in a major retail organization, highlighting the role of contextual forces in shaping change.

Novel perspectives in innovation research

In response to the conference theme, we tried to single out a group of papers under this heading that embody significant departures from the vade mecum, illustrating innovation in theory in the main, but also methodology. Two of the papers in this section (Bunker et al. and Igira) have already been reviewed. There were four other papers in this grouping.

The first was by Webb. An irony of the Scientific Method is that, although its epistemology is founded on the principle of replicability, replications are seldom carried out! Webb addressed this issue, presenting a useful taxonomy of seven different forms of replication strategies involving different combinations of method, theory and context; an exemplar of one such strategy, the 'methodsonly extension' is provided. The next paper by Burns and Light draws on Social Shaping of Technology (SST) which, like Actor Network theory, also problematizes the hardand-fast distinction between users and artefacts assumed by classical diffusion theory. Burns and Light apply an SST approach to the design and use of 'scripts' in call-centres, showing how operational staff modified the scripts in order to adapt to local exigencies. The next paper, by Bednar and Welch, addressed the barriers that all too often frustrate and obstruct organizational efforts to innovate, outlining a novel 'Contextual Analysis' approach that entails concentrating on actors' individual assumptions in order to understand better situational complexities.

The novelty of the final paper, that of Levine and Larson, was methodological rather than theoretical. Their concern was the identity of the MIS field as a coherent discipline and on how this should be studied, in terms of its development over time and the diffusion of its core knowledge. Various methods are possible: classification and citation analysis, expert forums, etc. The authors conclude that all methods have a part to play and that a composite of all will give the most complete picture.

\section{Software process improvement (SPI)}

Since its inauguration, WG8.6 has maintained a perennial interest in software engineering innovation. This theme united the papers in this section. The four papers addressed a broad range of concerns. Börjesson, Holmberg et al. were concerned that the conventional methods of SPI are founded on a 'problem-solving' paradigm, which can stultify creative thought. They are interested in the potential of 'appreciative enquiry' to stimulate a deeper level of critical reflection, although their case study reveals the refractoriness of solution-oriented mental habits. Börjesson, Baaz et al. examine a well-established SPI methodology, the GoalQuestion-Metric approach (Basili et al., 1994), deploying it 
in an action research framework. The rationale was to facilitate organizational learning and the evolution of the measurement mechanism over time. The results of a 6-year SPI initiative are presented.

Conboy and Fitzgerald, in contrast, addressed 'agile methods', presenting a Delphi study on attitudes and beliefs. The results indicate that such techniques appear, somewhat ironically, to be generally immutable and not therefore readily amenable to tailoring. They highlight the deficiencies inherent in agile methods, concluding with recommendations for industry-based proponents. In an apparent contrast, Parsons et al.'s questionnaire study of the use of methods confirmed previous research showing that software technologies (including agile methods) are characteristically deployed flexibly, adaptively and contingently by developers. Their findings show gains in productivity and quality, accrued apparently without extra cost.

\section{Actor network theory}

A clutch of six papers in all featured ANT in different guises as the primary theoretical lens. Two of the papers in this section have been reviewed. Of the others, Linderoth discussed the interesting notion of whether technology should be made 'visible' or 'invisible' through built-in inscriptions that affect and change processes in the host organization. He presents three case studies, two of which provide contrasting accounts of visibility. He argues that organizations need to make special efforts to keep technology visible, thus maintaining a degree of control that might otherwise be lost. Mohammed and Richardson, in contrast, attempt to combine contextualism with ANT in their study of the strategic processes entailed in constructing and implementing a customer services IS. They argue that the use of such a theoretical framework enables richer understanding into information and communications technology (ICT) implementation processes.

The final two papers examined possible rapprochements of ANT with other positions. Lin and Chiasson suggested that, rather than being cast in an oppositional relationship, ANT can be combined with concepts from diffusion theory. They exemplify their argument with a pilot study of mobile TV services in the UK. In contrast, Vuokki and Karsten presented an ambitious attempt to integrate concepts from complexity theory with ANT. A case setting is described (hospital intensive care) where they contend their framework is essential to address the complex work-practices and interactions involved.

Technological interlude: the case of RFID

This section of the Proceedings contained two papers, both addressing Radio Frequency IDentification (RFID) technology that has recently come to the fore as a potential breakthrough in the management of business supply chains. Huyskens and Loebbecke addressed the relatively slow progress of its adoption and elaborate an extended version of the Technology Acceptance Model as a generic factor model for studying adoption at the organizational level. A case study in the fashion industry is presented. Some factors (coercive power and top management support) were found to play a more influential role than others. RFID technologies are by their very nature immensely complex, and Brown and Bakru's thoughtful contribution provided a critique of traditional research methods. They argued that only the combination of process (or stage) models and diffusion perspectives are theoretically adequate for understanding such complex intra- and extra-organizational systems.

\section{Firm level adoption factors}

The papers in this final section all shared a concern with the adoption of technology at the level of the individual organization, and the factors that influence this. Vega et al.'s paper was selected for the Special Issue. The first of the remaining papers, by Zhang et al., takes up a similar theme, also assessing the effectiveness of governmental action. Their theoretical model is based on the TechnologyOrganization-Environment (TOE) framework, extended with ideas from institutional theory. In a survey of firms in the Shanghai area, they found that the effectiveness of government intervention varies across sectors and by the type of ownership. Ramdani and Kawalek also draw on TOE in looking at the adoption of enterprise systems among a number of medium-sized firms in the UK's Northwest region. They showed that adoption factors in this sector differ from ICT studies in, for example, larger organizations.

Finally, Abu-Samaha and Mansi provide us with insights into the challenges facing Jordanian Telecommunications (JT) as it seeks to recapture ground lost to competitors and changing market demands. The strategy includes the adoption of new and emerging technologies such as microwave and VoIP. They provide a rich description of these technologies, as well as a brief historical perspective on JT and its marketing environment.

\section{Finale}

It is salutary that in a Conference convened to promote diversity, it would appear that eclecticism and plurality in our field are under threat. Galliers rang the tocsin in his keynote address, warning of the dangers posed by current calls to limit our research to the IT artefact and its design. Such anxieties were echoed a fortiori by Truex and Holmström. They identity the sinister gathering of a 'supremacist tendency' in our field, which seeks to impose hegemony over method and topic. In scholarship in general, we are beset by potent institutional mechanisms exerting an ever-tighter grip on what goes and what does not. Those of us in the UK recently engaged in RAE $2008^{3}$ preparations know this only too well! In this audit-driven exercise, papers in top-ranking journals are prized above all else. Worries are surely legitimate about the future fate of the speculative, the unorthodox, the interdisciplinary and the maverick.

Douglas (2002) offers the contrast between 'dirt-affirming' and 'dirt-rejecting' philosophies. She speaks approvingly of those who reject the absolutism of monistic systems of truth. For Douglas, pluralism and 'healthy-mindedness' are one and the same; 'Purity is the enemy of change, of ambiguity and compromise' (ibid.: 200). This is Feyerabend's credo too. Engineering also well appreciates the epistemological importance of impurity; without mistakes and failures, there is no learning (Petroski, 2006). How dirt-affirming and healthy-minded are we in our tiny niche 
of WG8.6? Our epistemological experiment gives the opportunity to take stock. In our selection methodology, we have 'worked around' the purity agenda in the interests of inclusion and plurality. Let us now assess the extent to which the Conference has achieved its overarching aim of diversification in theory, method and empirical context? As noted above, we will use the 1997 conference as a rough benchmark (McMaster et al., 1997a).

Certainly we were fortunate in garnering a rich crop of papers, as Davis enthusiastically and generously observed:

As I reviewed the papers in the proceedings, I was struck by the diversity. There were papers on topics I understand well and there were papers on topics that I had not thought of before or not understood very well.... There are papers that advocate different approaches to research and open up a dialogue. In other words, the collection of papers in this volume can open minds and expand understanding.

In our Editorial, we noted the same eclecticism as an enduring feature of the Group's practice. The various efforts at theoretical rapprochement and hybridization were particularly notable, representing both sensible pragmatism and healthy irreverence for dogma. The substantive content of the Group's research has also moved on, with some new empirical terrain being opened up. But in other ways, we reflected that the main lineaments of the discourse had a familiar look. In terms of methodology, there was much the same mix of surveys, case studies and action research; domain-wise, the majority of papers addressed commercial rather than public organizations. Despite the critical role that ICT is playing in driving forward public sector 'modernization' across the globe, not a single paper explicitly addressed e-Government. This is as regrettable as it is salient, and we were driven to question this continuing infatuation with business. And what of theory, what movement had occurred here we asked? In 1997, there were two main factions: Diffusionism was the incumbent Goliath and ANT was the new kid on the block. ANT may since have waxed but diffusionism remains a powerful force, and they are still the chief protagonists. We wondered, with more than a soupçon of irony, whether they had merely switched roles and that ANT had now become the new orthodoxy! There is, of course, no explicit supremacist strategy at work here. Path dependency is enough to produce such conformity; it is easier to fit the mould than to break it.

Let us end by assessing how much the Group has achieved using its own practical objectives as a reference point. To what degree have the problems that originally animated our efforts been abated? In this respect, Davis contributed the following sobering reflection in his Foreword:

With over 10 years of research and conferences behind us, haven't the problems been solved? Unfortunately, technological innovation and diffusion continue to be difficult. The failure rate for new technologies and new systems remains high. In other words, there is still an important, viable mission for WG 8.6 in exploring issues of why some innovation efforts are successful and others fail. There is a need to continue to explore theoretical perspectives, methodologies, and organization issues.

In part, this stuttering progress could reflect our failure to engage with practitioners. While practical relevance has always been core to WG8.6's sense of mission and identity, in reality such engagement has been difficult to accomplish. In the present conference, for instance, almost all the contributions came from academics; the two practitioner papers were invited ones. Perhaps our enchantment with theory is partly responsible for this estrangement. The translation of the vernacular, phenomenal world of users into arcane, technical vocabularies is a form of mystification (White and Wastell, 2008) that inevitably creates insularity and hinders communication. Such anxieties clearly actuate Holmström and Truex's exhortation to 'drop our tools and hold our concepts lightly' in order to straddle the gap with practice.

These disconcerting thoughts invite the heretical reflection that redemption may lie not with more theory, but with less! Perhaps we should loosen our attachment to frameworks and models with all their Euclidean neatness and recondite terminology, and dig in the dirt that their geometric ordering inevitably creates and sweeps from view. Ciborra (2002: 21) put it well: 'How come researchers have come to privilege the geometry of a line connecting abstract concepts in a model while they remain blind to the blurred reality that any, even slight, ethnographic study would have revealed [italics added]'. Approaches such as ethnography and grounded theory may thus show the way to go. Latour (2004: 67) has uttered much the same cri du coeur, and we will sign off here, as we did in our original Editorial, by leaving the last word to the inadvertent begetter of the new orthodoxy! Horrified by our fetishization of theory, he writes mordantly:

My kingdom for a frame! Very moving; I think I understand your desperation. But no, ANT is pretty useless for that. Its main tenet is that actors themselves make everything, including their own frames, their own theories, their own contexts, their own metaphysics, even their own ontologies.... So the direction to follow would be more descriptions, I am afraid.

\section{Notes}

1 The translation is problematic, as we noted in our Editorial. But with the help of two native German speakers, we offered the following as our rendition: 'These days, order is mostly there where nothing is. It is a deficiency symptom'. Although this literal translation had a 'clunky' feel, we decided to remain loyal to it, fearing the loss of relevant metaphorical content or the addition of spurious new meaning.

2 Galileo and the Copernican revolution is the main exemplar used by Feyerabend. Recent sociological narratives of scientific practice bear out the same argument (e.g. Latour, 1999); these accounts reveal working scientists as pragmatists and tricksters, far removed from the popular stereotype of the disinterested scholar uncovering a priori facts.

3 The Research Assessment Exercise (RAE) is a periodic survey of research performance across the UK higher education sector. 
This is not the place to rehearse the dysfunctions of the RAE; they are rich and varied, and much lamented and lampooned elsewhere, for example, Elton (2000) and Pierce (2000).

\section{References}

Basili, V.G., Caldiera, G. and Rombach, H.D. (1994). The Goal/Question Metric Approach, in J. Marciniak (ed.) Encyclopaedia of Software Engineering (Volume 1), New York: John Wiley \& Sons, pp. 528-532.

Ciborra, C. (2002). The Labyrinths of Information: Challenging the wisdom of systems, Oxford: Oxford University Press.

Douglas, M. (2002). Purity and Danger, London: Routledge.

Elton, L. (2000). The UK Research Assessment Exercise: Unintended consequences, Higher Education Quarterly 54(3): 74-83.

Feyerabend, P. (1993). Against Method, London: Verso.

Flynn, D. and Gregory, P. (2004). The Use of Theories in 20 Years of WG8.2 Empirical Research, in B. Kaplan, D.P. Truex, D. Wastell, A.T. Wood-Harper and J.I. DeGross (eds.) Information Systems Research: Relevant theory and informed practice, Boston: Kluwer, pp. 365-388.

Latour, B. (1987). Science in Action, Cambridge: Harvard University Press.

Latour, B. (1999). Pandora's Hope: An essay on the reality of science studies, Cambridge: Harvard University Press.

Latour, B. (2004). On Using ANT for Studying Information Systems: A (somewhat) socratic dialogue, in C. Avgerou, C. Ciborra and F. Land (eds.) The Social Study of Information and Communication Technology: Innovation, actors and contexts, Oxford: Oxford University Press.

McMaster, T., Mumford, E., Swanson, E.B., Warboys, B. and Wastell, D.G. (1997a). Facilitating Technology Transfer Through Partnership: Learning from practice and research, London: Chapman \& Hall.

McMaster, T., Vidgen, T. and Wastell, D. (1997b). Technology Transfer: Diffusion or translation?, in T. McMaster, E. Mumford, D. Wastell, E. Swanson and B. Warboys (eds.) Facilitating Technology Transfer Through Partnership: Learning from practice and research, London: Chapman \& Hall, pp. 64-75.

McMaster, T., Wastell, D.G., Fernley, E. and DeGross, J. (2007). Organizational Dynamics of Technology-Based Innovation: Diversifying the research agenda, Boston: Springer.

Petroski, H. (2006). Success Through Failure: The paradox of design, Princeton: Princeton University Press.

Pierce, N. (2000). Why it is Fundamentally Stupid for a Business School to Try to Improve its Research Assessment Exercise Score, European Journal of Marketing 34(1/2): 27-35.

Stoler, A.L. (2002). Colonial Archives and the Arts of Governance, Archival Science 2: 87-109.

Wastell, D. and McMaster, T. (2007). Conferences as Epistemological Experiments: Purity, plurality, and the politics of knowledge, in T. McMaster, D. Wastell, E. Ferneley and J. DeGross (eds.) Organizational Dynamics of Technology-Based Innovation: Diversifying the research agenda, Boston: Springer, pp. 1-12.

White, S. and Wastell, D. (2008). Theoretical Discourse and Moral Negotiation in Child Welfare: The saga of evie and seb, in C. Candlin and S. Sarangi (eds.) Handbook of Communication in Organisations and Professions, Berlin: Mouton de Gruyter, in press.

\section{Appendix: Full Contents of the Conference Proceedings}

Part 1: Keynotes and invited papers

Galliers, R.D. Organizational Dynamics of TechnologyBased Innovation: Diversifying the information systems research agenda.

Carter, D. Turning the Digital Divide into a Digital Dividend: Some experiences from Manchester, UK.

Truex, D., and Holmström, J. Dropping Your Tools: The diversity of the research agenda in organizational dynamics of technology-based innovation.
Leon, G. Cooperative Models for Information Technology Transfer in the Context of Open Innovation.

Newman, M. and Zhu, S. Process Modelling Information Systems Development: The SellCo Case.

Part 2: Novel perspectives in innovation research

Bunker, B., Kautz, K and Anhtuan, A. An Exploration of Information Systems Adoption: Tools \& skills as cultural artefacts - The case of a management information system.

Webb, B. Re-Searching Commonality Differently: Subjectively replicating a theory of multimedia systems development.

Igira, F.T. The Situatedness of Work Practices and Organizational Culture: Implications for information systems innovation uptake.

Burns, B. and Light, B. User-Led Innovation in Call Center Knowledge Work: A social shaping perspective.

Bednar, P.M. and Welch, C. Contextual Analysis as Support for Successful Innovation in Complex Environments.

Larsen, T.J. and Levine, L. The Identity, Dynamics, and Diffusion of MIS.

\section{Part 3: Software process improvement}

Börjesson, A., Holmberg, L., Holmström, H. and Nilsson, A. Use of Appreciative Inquiry in Successful Process Improvement: An action research study.

Börjesson, A., Baaz, A, Pries-Heje, J. and Timmerås, M. Measuring Process Innovations and Improvements.

Conboy, K. and Brian Fitzgerald, B. The Views of Experts on the Current State of Agile Method Tailoring.

Parsons, D. The Impact of Methods and Techniques on Outcomes from Agile Software Development Projects.

Part 4: Actor network theory

Elbanna, A.R. The Inertia of ERP Projects: Diffusion or drift?

Linderoth, H.C.J. Make Technology Invisible, or Keep it Visible? The Role of Intra-organizational Transfer and Integration of Project Outcomes.

Mohammed, T.A. and Richardson, H.J. Implementation of a Customer Services Information Systems Strategy in a Higher Education Context: An integrative perspective.

Rodon, J., Pastor, J.A. and Sesé, F. The Dynamics of an IOIS in the Seaport of Barcelona: An ANT perspective.

Lin, Su-Yi and Chiasson, M. Dynamic Approach to Context in Diffusion Research: An actor network theory study of mobile-TV service.

Vuokko, R. and Karsten, H. Working with Technology in Complex Networks of Interaction.

Part 5: Technological interlude: the case of RFID

Huyskens, C. and Loebbecke, C. RFID Adoption: Theoretical concepts and their practical application in fashion.

Brown, A. and Bakhru, A. Information Systems Innovation Research and the Case of RFID.

Part 6: Firm-level adoption factors

Vega, A., Chiasson, M., and David Brown, D. Extending the Research Agenda on Diffusion of Innovations: The role of 
public programs in the diffusion of e-business innovations.

Zhang, C., Cui, L. Huang, L. and Zhang, C. Exploring the Role of Government in Information Technology Diffusion: An empirical study of IT usage in Shanghai firms.

Ramdani, B. and Kawalek, P. SME Adoption of Enterprise Systems in the Northwest of England: An environmental, technological, and organizational perspective.

Abu-Samaha A.M., and Mansi, I. Information Technology Diffusion in the Jordanian Telecom Industry.

Part 7: Position papers

Adams, C. Challenges for Creativity and Innovation in Mobile and Transient Virtual Environments.

Baloh, P. and Burke, M. Attaining Organizational Innovations: Better smart than fast.

Bray, D. Knowledge Ecosystems: A theoretical lens for organizations confronting hyperturbulent environments.

Costello, G., Donnellan, B. Gleeson, I and Rochford, C. The Triple Helix, Open Innovation, and the DOI Research Agenda.

Ginn, M. Bringing an Integral Approach to the Field of Technology Diffusion Research.

Higgins, A. Software Innovation as Maintenance: Theorizing the social in software maintenance.

Hossain, L., Shenshen, Z. and Murshed S.H. Exploring Structural Changes of the Communications Network During Organizational Crisis.
Kirsch, L.J., Slaughter, S. and Haney, M.H. Research and Information Systems: How information systems are transforming the nature of science (and what does this mean for IS researchers).

Matthias, T., Miller, L., Caputi, P., Jayasuriya, R. and Willis, D. Psychological Reactance and Information Systems Adoption.

Sauer, C., Reich, B.H and Gemino, A. The New Challenge of Business Value: Time to link project management performance with adoption research?

Singh, R., Wood, B. and Wood-Harper, T. Socio-Technical Design of the 21st Century: A vision.

Tan, C-H., Yang, X. and Teo, H-H. When Counterfactual Thinking Meets the Technology Acceptance Model: An investigation.

Wastell, D. The Myth of Alignment.

Wendorff, P. Coaching the Application of Agile Software Development.

Part 8: Panels

Land, F., Bryant, A., Eason, K., Mitleton-Kelly, E. and Wastell, D. Complexity Theory and the Diffusion of Innovations.

Williams, M.D., Dwivedi Y.K., Middleton, C., Wilson, D., Falch, M. Alex Schulz, A. and Weerakkody, V., Papazafeiropoulou, A., Ramdani, B. and Gholami, R. Global Diffusion of Broadband: Current state and future directions for investigation. 